\title{
Management of refractory macular hole with blood and gas-assisted autologous neurosensory retinal free flap transplantation: a case report
}

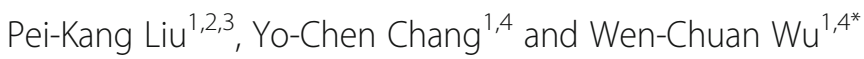

\begin{abstract}
Background: Macular hole $(\mathrm{MH})$ may become refractory if the hole does not close after multiple surgeries. We provide a modified surgical technique for refractory $\mathrm{MH}$ repair with neurosensory retinal free flap transplantation.

Case presentation: To treat a 68-year-old female patient with refractory $\mathrm{MH}$ after multiple surgeries, we harvested a neurosensory retinal free flap with a 2-MH diameter area. A drop of whole blood was placed within the $\mathrm{MH}$ as an adhesive to fix the neurosensory retinal free flap at the $\mathrm{MH}$ under gas tamponade. Two months after surgery, optical coherence tomography $(\mathrm{OCT}$ ) revealed closure of the $\mathrm{MH}$. The flap was visible on OCT and had filled the $\mathrm{MH}$ without overlapping the neurosensory retina. The patient's best-corrected visual acuity (BCVA) improved from 20/500 preoperatively to 20/50 at 2 months postoperatively.

Conclusions: Using whole blood as an adhesive to aid in the fixation of an autologous neurosensory retinal free flap under gas tamponade provides another option for patients with refractory $\mathrm{MH}$ due to multiple prior surgeries.
\end{abstract}

Keywords: Autologous, Blood, Gas, Neurosensory, Free retinal flap, Transplantation, Refractory, Macular hole

\section{Background}

With improvements in the surgical techniques for treating macular hole $(\mathrm{MH})$, the success rate of $\mathrm{MH}$ repair is currently greater than $90 \%[1,2]$. However, in some cases, the $\mathrm{MH}$ still fails to close after repeated surgery, especially in patients with high levels of myopia [3] or chronic MH [4]. Several surgical techniques have been reported for treating refractory $\mathrm{MH}$, such as extended internal limiting membrane (ILM) peeling, autologous free ILM flap transplantation, and lens capsular flap transplantation, [5] with or without an adjuvant blood component [6].

Grewal and Mahmoud reported a novel method for refractory myopic $\mathrm{MH}$ repair, which involved an autologous

\footnotetext{
* Correspondence: wcwu.oph@gmail.com

${ }^{1}$ Department of Ophthalmology, Kaohsiung Medical University Hospital, Kaohsiung Medical University, No. 100, Tzyou 1st Road, Kaohsiung 807, Taiwan

${ }^{4}$ Department of Ophthalmology, School of Medicine, Kaohsiung Medical University, 100, Shih-Chuan 1st Road, Kaohsiung 80708, Taiwan Full list of author information is available at the end of the article
}

neurosensory retinal free flap of 2 disc diameters, perfluoro-n-octane heavy liquid (PFC; Perfluoron, Alcon) instillation, and direct PFC-silicone oil exchange [7]. In this technique, the surgeon needs to use both PFC and silicone oil to stabilize the free retinal flap. A small amount of PFC may remain in the eye, and the removal of silicone oil may be inevitable in the future. Flap dislocation after silicone oil removal is also possible. In addition, the relatively large size (2 disc diameters) of the retinal free flap may result in neurosensory retinal overlap.

To improve the surgical outcome and simplify the technique, we describe a newly modified technique involving the use of blood as an adhesive to aid in the fixation of the retinal free flap under gas tamponade with $15 \%$ perfluoropropane $\left(\mathrm{C}_{3} \mathrm{~F}_{8}\right)$.

\section{Case presentation}

A 68-year-old female underwent phacoemulsification + intraocular lens implantation + pars plana vitrectomy $(\mathrm{PPV})+\mathrm{ILM}$ peeling $+18 \%$ sulfur hexafluoride $\left(\mathrm{SF}_{6}\right)$ 
A

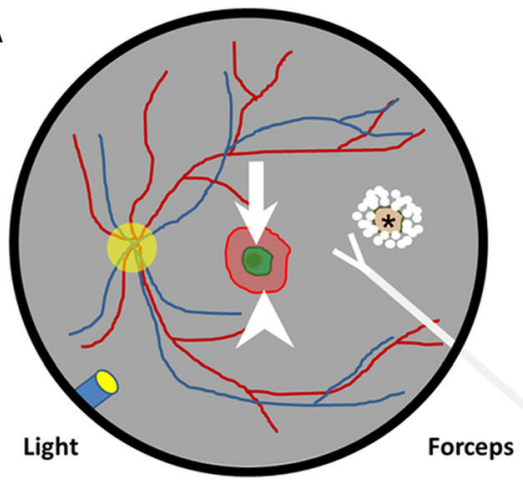

B

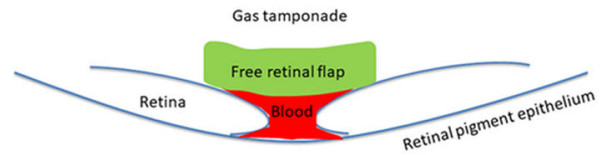

Fig. 1 Schematic drawing of a surgical technique for the treatment of refractory MH involving autologous transplantation of a neurosensory retinal free flap using blood as an adhesive under gas tamponade. a. A neurosensory retinal free flap (white arrow) was harvested from the temporal side of the macula (asterisk) and was placed over the blood (white arrowhead) at the MH. $\mathbf{b}$. Cross-sectional view of the neurosensory retinal free flap adhered to the blood in the $\mathrm{MH}$ area. $\mathrm{MH}$, macular hole

tamponade in January 2016 due to an epiretinal membrane and a lamellar MH. Unfortunately, macular hole retinal detachment (MHRD) occurred one month after surgery. She received PPV + extended ILM peeling + silicone oil tamponade in February 2016 and underwent removal of silicone oil in October 2016. The retina had attached well, although the MH became refractory, and her best-corrected visual acuity (BCVA) was 20/500. She underwent two PPV + free ILM flap transplantation + 15\% $\mathrm{C}_{3} \mathrm{~F}_{8}$ treatments in April 2017 and July 2017, with unsatisfactory results. Due to her repeated surgeries, an autologous free ILM flap could not be harvested. We decided to perform a neurosensory retinal free flap transplantation for the repair of this refractory $\mathrm{MH}$ after discussion with the patient.

A standard 25-g, 3-port PPV (Constellation; Alcon) was performed under general anesthesia. Endolaser photocoagulation was applied to outline the retinal free flap at the temporal retina. The neurosensory retinal free flap was approximately twice the diameter of the $\mathrm{MH}$. The retina was cut with vertical scissors along the inner edge of the laser spots and was gently dissected with back-flush needle irrigation until a neurosensory retinal free flap with a $2-\mathrm{MH}$ diameter area was harvested. The infusion was stopped temporarily to prevent turbulent flow. A drop of whole blood was placed within the $\mathrm{MH}$, and the neurosensory retinal free flap was then placed on the blood. We performed fluid-gas exchange and flushed the vitreous cavity with $15 \% \mathrm{C}_{3} \mathrm{~F}_{8}$ at the end of the surgery (Fig. 1). All of the techniques were performed under standard 25-g, 3-port PPV. We did not use a bimanual approach under chandelier illumination (see Additional file 1). The patient was instructed to maintain a prone position for 14 days postoperatively and to avoid any unnecessary movement.

Three weeks after surgery, optical coherence tomography (OCT) revealed closure of the $\mathrm{MH}$. The flap was visible on OCT and had filled the $\mathrm{MH}$ without overlapping of the neurosensory retina. The 2-month postoperative OCT examination still showed the MH closure. The patient reported an improvement of visual acuity and a decrease in her scotoma area. The patient's BCVA improved from $20 / 500$ preoperatively to $20 / 50$ at 2 months postoperatively.

\section{Discussion}

Refractory $\mathrm{MH}$ remains challenging for vitreoretinal surgeons and may progress to MHRD, which is a vision-threatening complication. Several methods, including extended ILM peeling, autologous free ILM flap transplantation, lens capsular flap transplantation, subretinal balanced salt solution injection to create macular detachment, and revitrectomy with autologous platelet concentrate (APC)/whole blood and gas tamponade, have been reported for refractory $\mathrm{MH}$ repair $[5,8,9]$. All these methods facilitate the closure of most MHs. However, a few patients still have a persistent $\mathrm{MH}$ even after multiple surgeries, and a free ILM flap may not be available. Furthermore, a lens capsular flap cannot be harvested in pseudophakic patients. Therefore, neurosensory retinal free flap transplantation becomes a reasonable and feasible method for the repair of a refractory $\mathrm{MH}$.

Grewal and Mahmoud reported a novel method for the treatment of refractory $\mathrm{MH}$ with an autologous neurosensory retinal free flap with a 2-disc diameter under PFC assistance and silicone oil tamponade [7]. Parolini et al. then introduced another method involving an autologous choroid-retinal pigment epitheliumneurosensory retinal graft to treat end-stage exudative age-related macular degeneration [10]. Both methods provide potential surgical alternatives for the treatment of refractory $\mathrm{MH}$. In the technique, the surgeons use both PFC and silicone oil to stabilize the retinal 
free flap. However, the stability of the transplanted retinal flap after removal of the silicone oil is unknown. Recurrent neurosensory retinal flap dislocation may occur.

Purtskhvanidze et al. reported the use of APC or whole blood with gas tamponade for refractory $\mathrm{MH}$ repair [8]. In their report, revitrectomy with whole blood and gas achieved a lower closure rate than that with APC and gas (7.1\% versus $85.2 \%$, respectively). In addition, the retinal free flap was noted on OCT (Fig. 2b). Therefore, we speculate that closure of the refractory $\mathrm{MH}$ in this case was not from the effect of whole blood.

Whole blood contains serum, coagulants, albumin, and globulin and can be prepared as blood glue [11]. Therefore, it is reasonable to use whole blood as an adhesive to fix a neurosensory retinal free flap at a $\mathrm{MH}$ under gas tamponade. However, the relatively large size (2 disc diameters) of the retinal free flap may result in neurosensory retinal overlap. Therefore, we modified the size to $2 \mathrm{MH}$ diameters to prevent neurosensory retinal overlap. Similar to the case reported by Grewal and Mahmoud, the restoration of retinal stratification with a corresponding increase in BCVA suggests that the autologous neurosensory retinal free flap may partially
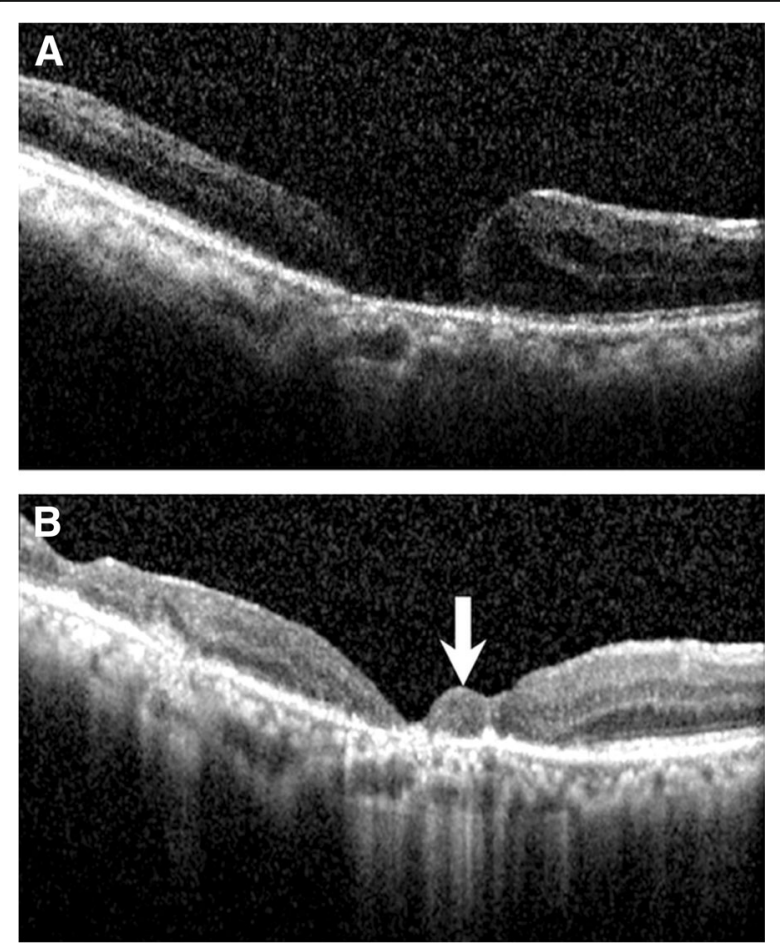

Fig. 2 Serial OCT images. a. Preoperative OCT showing a chronic $\mathrm{MH}$. b. Postoperative OCT showing closure of the $\mathrm{MH}$ with the neurosensory retinal free flap (white arrow) inside the $\mathrm{MH}$. The patient's BCVA improved from 20/500 preoperatively to 20/50 at 2 months postoperatively. OCT, optical coherence tomography; $\mathrm{MH}$, macular hole; BCVA, best-corrected visual acuity maintain retinal function in addition to acting as a scaffold for glial cell proliferation.

There are still several limitations to this technique. First, the most appropriate size of the neurosensory retinal free flap remains unclear since the free flap may contract after implantation into the MH. Second, due to the limited number of cases and relatively short follow-up times, the long-term outcomes and possible complications are unknown. We would like to emphasize that harvesting a neurosensory retinal free flap for transplantation remains the last resort in difficult cases to repair refractory $\mathrm{MHs}$ that fail to close after repeated surgeries. Third, a better adhesive or tissue glue for the fixation of the retinal free flap may improve the outcome. Additional experience may help refine the technique and clarify the anatomical and functional results.

\section{Conclusion}

In conclusion, using whole blood as an adhesive to aid in the fixation of an autologous neurosensory retinal free flap under gas tamponade provides another choice for patients who are refractory to treatment due to prior multiple surgeries and may decrease the use of PFC and silicone oil, although a proper trial or further studies are necessary to confirm the effect. We present this modified technique with a lower learning curve in an attempt to simplify the surgical procedure. The method seems to be suitable, reasonable, and affordable for every patient. We hope to provide another option to all vitreoretinal surgeons worldwide for refractory or chronic $\mathrm{MH}$ repair.

\section{Additional file}

Additional file 1: Surgical video. (MP4 $70714 \mathrm{~kb})$

\section{Abbreviations}

APC: autologous platelet concentrate; BCVA: Best-corrected visual acuity; $\mathrm{C}_{3} \mathrm{~F}_{8}$ : Perfluoropropane; ILM: Internal limiting membrane; $\mathrm{MH}$ : Macular hole; MHRD: Macular hole retinal detachment; OCT: Optical coherence tomography; PFC: Perfluoro-n-octane heavy liquid; PPV: Pars plana vitrectomy; $\mathrm{SF}_{6}$ : Sulfur hexafluoride

\section{Acknowledgments}

This topic was presented in part at the Spring Meeting of the Taiwan Retinal Society: April 15, 2018; Kaohsiung, Taiwan.

\section{Funding}

This study did not require any specific grant from any public, commercial or not-for-profit funding agency. No government or nongovernment financial support was involved in the work for this submission.

\section{Availability of data and materials}

All the data are contained and presented within the manuscript, figures, and additional supporting files (Additional file 1).

The datasets used and analyzed in the current study are available from the corresponding author upon reasonable request. 


\section{Authors' contributions}

PKL drafted this manuscript, collected the data, and reviewed the literature. YCC and WCW reviewed the literature and collected the data. WCW and PKL performed the surgery. WCW critically reviewed the final manuscript. All authors confirmed and approved the final manuscript.

\section{Ethics approval and consent to participate}

Not applicable.

\section{Consent for publication}

Written informed consent was obtained from the patient for publication of this case report. A copy of the written consent is available for review by the Editor-in-Chief of this journal.

\section{Competing interests}

The authors declare that they have no competing interests.

\section{Publisher's Note}

Springer Nature remains neutral with regard to jurisdictional claims in published maps and institutional affiliations.

\section{Author details}

'Department of Ophthalmology, Kaohsiung Medical University Hospital, Kaohsiung Medical University, No. 100, Tzyou 1st Road, Kaohsiung 807, Taiwan. ${ }^{2}$ Department of Ophthalmology, Yuan's General Hospital, No. 162 Cheng Kung 1st Road, Kaohsiung 80249, Taiwan. ${ }^{3}$ Institute of Biomedical Sciences, National Sun Yat-Sen University, 70 Lienhai Rd, Kaohsiung 80424, Taiwan. ${ }^{4}$ Department of Ophthalmology, School of Medicine, Kaohsiung Medical University, 100, Shih-Chuan 1st Road, Kaohsiung 80708, Taiwan.

Received: 29 May 2018 Accepted: 28 August 2018

Published online: 03 September 2018

\section{References}

1. Ip MS, Baker BJ, Duker JS, Reichel E, Baumal CR, Gangnon R, Puliafito CA: Anatomical outcomes of surgery for idiopathic macular hole as determined by optical coherence tomography. Archives of ophthalmology (Chicago, III : 1960) 2002, 120(1):29-35.

2. Brooks HL Jr. Macular hole surgery with and without internal limiting membrane peeling. Ophthalmology. 2000;107(10):1939-48. discussion 1948-1939

3. Wu TT, Kung YH. Comparison of anatomical and visual outcomes of macular hole surgery in patients with high myopia vs. non-high myopia: a case-control study using optical coherence tomography. Graefe's archive for clinical and experimental ophthalmology = Albrecht von Graefes Archiv fur klinische und experimentelle Ophthalmologie. 2012;250(3):327-31.

4. Thompson JT, Sjaarda RN, Lansing MB: The results of vitreous surgery for chronic macular holes. Retina (Philadelphia, Pa) 1997, 17(6):493-501.

5. Tam ALC, Yan P, Gan NY, Lam WC: The current surgical management of large, recurrent, or persistent macular holes. Retina (Philadelphia, Pa) 2018.

6. Lai CC, Hwang YS, Liu L, Chen KJ, Wu WC, Chuang LH, Kuo JZ, Chen TL. Blood-assisted internal limiting membrane peeling for macular hole repair. Ophthalmology. 2009;116(8):1525-30.

7. Grewal DS, Mahmoud TH. Autologous neurosensory retinal free flap for closure of refractory myopic macular holes. JAMA ophthalmology. 2016; 134(2):229-30

8. Purtskhvanidze K, Fruhsorger B, Bartsch S, Hedderich J, Roider J, Treumer F. Persistent full-thickness idiopathic macular hole: anatomical and functional Outcome of Revitrectomy with autologous platelet concentrate or autologous whole blood. Ophthalmologica Journal international d'ophtalmologie International journal of ophthalmology Zeitschrift fur Augenheilkunde. 2018;239(1):19-26.

9. Szigiato AA, Gilani F, Walsh MK, Mandelcorn ED, Muni RH Induction of macular detachment for the treatment of persistent or recurrent idiopathic macular holes. Retina (Philadelphia, Pa) 2016, 36(9):1694-1698.

10. Parolini B, Grewal DS, Pinackatt SJ, Baldi A, Di Salvatore A, Besozzi G, Finzi A, Cardillo D, Mahmoud TH: Combined autologous transplantation of neurosensory retina, retinal pigment epithelium, and choroid free grafts. Retina (philadelphia, pa) 2017.

11. Lin H, Gunasekaran S. Cow blood adhesive: characterization of physicochemical and adhesion properties. Int J Adhes Adhes. 2010;30(3): 139-44.

Ready to submit your research? Choose BMC and benefit from:

- fast, convenient online submission

- thorough peer review by experienced researchers in your field

- rapid publication on acceptance

- support for research data, including large and complex data types

- gold Open Access which fosters wider collaboration and increased citations

- maximum visibility for your research: over $100 \mathrm{M}$ website views per year

At $\mathrm{BMC}$, research is always in progress.

Learn more biomedcentral.com/submissions 